\title{
The Producing Technology of Resistant Starch from Buckwheat Using Ultrasonic Treatment
}

\author{
Wang $L^{1 *}$ and Bai $X^{2}$ \\ ${ }^{1}$ The College of Life Science, Yangtze University, Jingzhou, Hubei, China
}

${ }^{2}$ The First People's Hospital of Jingzhou, Jingzhou, Hubei, China

\begin{abstract}
Resistant Starch (RS) has various functions in controlling the Glycemic Index (GI), lowering concentration of cholesterol and triglycerides, inhibiting fat accumulation, preventing colonic cancer, reducing gall stone formation, maintaining intestinal tract healthy and enhancing the absorption of minerals. Elevated RS in food is an important and effective approach for public health. RS is also an important material for industries. In this paper, the producing technologies of resistant starch from buckwheat were investigated. The results showed that the optimum parameters for producing technology of resistant starch from buckwheat using ultrasonic treatment are ultrasonic treatment time is $20 \mathrm{~min}$, ultrasonic power is $300 \mathrm{~W}$, and ultrasonic frequency is $63 \mathrm{KHz}$, Solid-to-liquid ratio 1:8.
\end{abstract}

Keywords: Buckwheat; Resistant Starch (RS); Orthogonal design

\section{Introduction}

Resistant Starch (RS) is also called enzyme resistant starch, definited as the starch and starch degradation products which cannot be digested and absorbed in the healthy small intestine of human [1]. RS provides functional properties in controlling GI [2], lowering concentration of cholesterol and triglycerides [3,4], inhibiting fat accumulation [5], preventing colonic cancer [6], reducing gall stone formation [7], maintaining intestinal tract healthy $[8,9]$ and enhancing the absorption of minerals [10]. RS a novel insulin receptor sensitizer is benefited to diabetes, which can enhance insulin function and regulate blood glucose [11]. Elevated RS in food is an important and effective approach for public health. RS is also an important material for industries. Buckwheat (Fagopyrum esculentum) belonging to plants of the genus Polygonaceae Buckwheat, is edible biologic medicine with relative high starch content, with various values of nutritional therapy health care [12].

The mechanism of RS formation is largely unknown. There are several factors affect the RS formation. It's reported that RS content is positive related to AC $[13,14]$. Starch granule size and structure are related the RS content. Starch granule in potato is larger than that in cereals, the potato starch digested more slowly than that of cereals [15]. Starch Crystalline structure can be classified into A type, B type and $\mathrm{C}$ type, according $\mathrm{X}$-ray scattering pattern. The digestibility of the starch with B types less than A type, $C$ type in the middle [16]. The chain length of amylose and amylopectin is another major factor affect the RS formation. RS increase according Degree of Polymerization (DP) of amylose (from $10 \mathrm{DP}$ to $610 \mathrm{DP}$ ) by hydrothermal treatment with retention [17]. The effect of the chain length amylopectin on RS formation is unclear in detail. It reported that amylopectin starch debranched by Pullulanase followed by heat-processing can increase RS content [18]. It's due to long unbranched chains of amylopectin involve into RS formation [19]. Other components in cell, such as protein, lipid, cellulose can also effect RS content [20,21]. Among them, Lipids is most important effect on RS formation. Lipids can decrease RS content significantly [19]. Food additives and food processing technologies are another factors can affect RS content [22,23]. We analyzed the effects of the preparing conditions to buckwheat RS content and got the optimal preparing conditions for buckwheat RS content. The results of this work will lay the foundation of theory and application for the further study of buckwheat RS.

\section{Materials and Methods}

\section{Preparation of Buckwheat flour}

Buckwheat was purchased from Jilin City. Buckwheat was grinded into flour using flour mill, then filtered using 200 mesh sieve.

\section{Determination of RS content}

RS content was measured according to AOAC method (2002.02) with a slight modification [24]. $100 \pm 1 \mathrm{mg}$ milled maize flour (only endosperm) were accurately weighed and placed directly into screwcap tubes $(16 \times 125 \mathrm{~mm}) .500 \mu \mathrm{L}$ water was added into each tube, then boiled in electric cooker for $20 \mathrm{~min}$ and at warm keeping status at $50^{\circ} \mathrm{C}$ for $10 \mathrm{~min}$. Tubes were taken out and cooled to room temperature. $\mathrm{KCl}-\mathrm{HCl}$ buffer $(\mathrm{pH}=1.5)$ containing $6 \mathrm{IU} / \mathrm{mg}$ pepsin was added into each tube and the rice floury was ground and dispersed by a stirring rod, mimicking the chewing in mouth and warmed at $37^{\circ} \mathrm{C}$ for $1 \mathrm{~h}$. Other procedures were carried out as described in the method AOAC (2002.02) [24].

\section{The optimization of the preparation process of buckwheat RS}

To optimize the preparation process of buckwheat RS, the major factors and their levels were determined according the effects of various factors (such as ultrasonic power, ultrasonic frequency, ultrasonic treatment time, heating temperature after ultrasonic treatment, Solid-to-Liquid ratio (S/L) using ultrasonic treatment) on RS content using ultrasonic treatments. The optimum preparation conditions of buckwheat RS were further determined using orthogonal test.

*Corresponding author: Wang L, The College of Life Science, Yangtze University Jingzhou, Hubei, China, Tel: +8607168066257; E-mail: ljwang516@126.com

Received July 19, 2017; Accepted July 27, 2017; Published August 03, 2017

Citation: Wang L, Bai X (2017) The Producing Technology of Resistant Starch from Buckwheat Using Ultrasonic Treatment. Agrotechnology 6: 161. doi: 10.4172/21689881.1000161

Copyright: ( 2017 Wang L, et al. This is an open-access article distributed under the terms of the Creative Commons Attribution License, which permits unrestricted use, distribution, and reproduction in any medium, provided the original author and source are credited. 
Citation: Wang L, Bai X (2017) The Producing Technology of Resistant Starch from Buckwheat Using Ultrasonic Treatment. Agrotechnology 6: 161. doi: 10.4172/2168-9881.1000161

Page 2 of 3

\section{Results and Discussion}

\section{The effects of ultrasonic frequency on buckwheat RS content}

The buckwheat starch was heated at $100^{\circ} \mathrm{C}$ for 20 min after using different ultrasonic frequency for $30 \mathrm{~s}$ with 1:2 solid-to-liquid ratio, then after storage at $4^{\circ} \mathrm{C}$ for $24 \mathrm{~h}$, dried at $50^{\circ} \mathrm{C}$ for $18 \mathrm{~h}$. The RS content of the dried buckwheat was analyzed. The optimum ultrasonic frequency is $40 \mathrm{KHz}$ (Figure 1).

\section{The effects of ultrasonic power on buckwheat RS content}

The buckwheat starch was heated at $100^{\circ} \mathrm{C}$ after using different ultrasonic power for $30 \mathrm{~s}$ with 1:2 solid-to-liquid ratio, then after storage at $4^{\circ} \mathrm{C}$ for $24 \mathrm{~h}$, dried at $50^{\circ} \mathrm{C}$ for $18 \mathrm{~h}$. The RS content of the dried buckwheat was analyzed. The optimum ultrasonic power is 300 W (Figure 2).

\section{The effects of ultrasonic treatment time on buckwheat RS content}

The buckwheat starch was heated at $100^{\circ} \mathrm{C}$ after using $28 \mathrm{KHz}$ ultrasonic power for different time with 1:2 solid-to-liquid ratios, then after storage at $4^{\circ} \mathrm{C}$ for $24 \mathrm{~h}$, dried at $50^{\circ} \mathrm{C}$ for $18 \mathrm{~h}$. The RS content of the dried buckwheat was analyzed. The optimum ultrasonic treatment time is $20 \mathrm{~min}$ (Figure 3).

Effects of heating temperature after ultrasonic treatment on buckwheat RS

The buckwheat starch was heated at different temperature after using $28 \mathrm{KHz}$ ultrasonic power for 30s with 1:2 solid-to-liquid ratio, and then heated at different temperature after storage at $4^{\circ} \mathrm{C}$ for 24 $\mathrm{h}$, dried at $50^{\circ} \mathrm{C}$ for $18 \mathrm{~h}$. The RS content of the dried buckwheat was analyzed. The optimum heating temperature after ultrasonic treatment is $120^{\circ} \mathrm{C}$ (Figure 4 ).

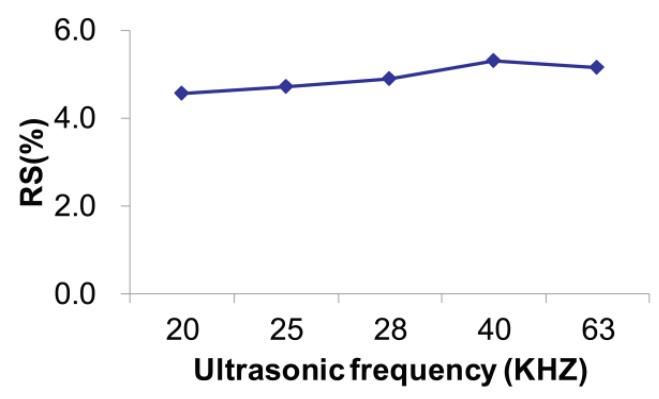

Figure 1: Effects of ultrasonic frequency on buckwheat RS.

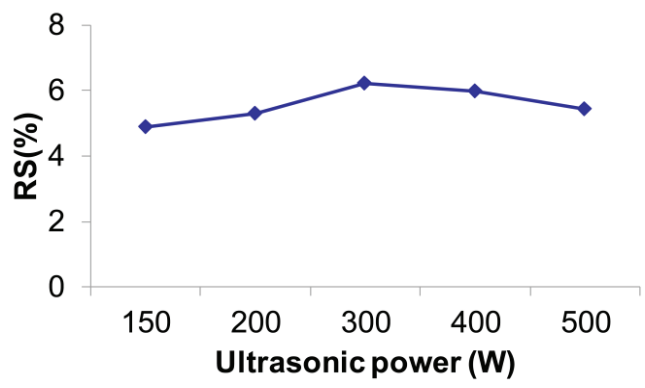

Figure 2: Effects of ultrasonic power on buckwheat RS.
The effects of solid-to-liquid ratio using ultrasonic treatment on buckwheat RS content

The buckwheat starch was heated at $100^{\circ} \mathrm{C}$ after using $28 \mathrm{KHz}$ ultrasonic power for 30s with different solid-to-liquid ratio, then after storage at $4{ }^{\circ} \mathrm{C}$ for $24 \mathrm{~h}$, dried at $50^{\circ} \mathrm{C}$ for $18 \mathrm{~h}$. The RS content of the dried buckwheat was analyzed. The optimum solid-to-liquid ratio using ultrasonic treatment is 1:6 (Figure 5).

\section{RS processing orthogonal experiment}

According the effects of individual factors on the RS contents, orthogonal experiments were conducted using microwave power, treatment time using microwave power, solid-to-liquid ratio and annealing time after microwave treatment as factors and RS content as index (Tables 1 and 2).

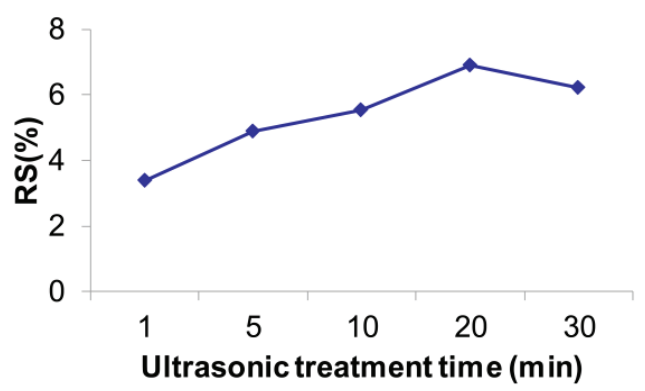

Figure 3: Effects of ultrasonic treatment time on buckwheat RS.

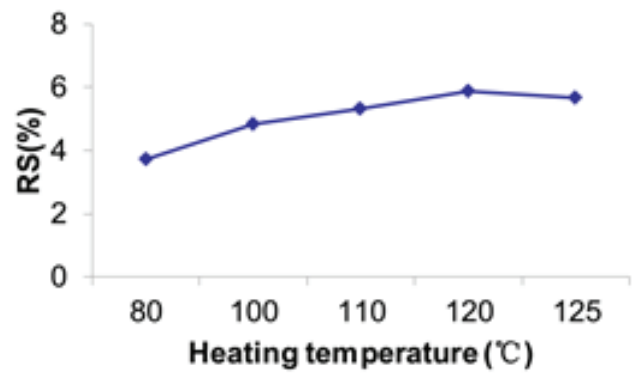

Figure 4: Effects of heating temperature after ultrasonic treatment on buckwheat RS.

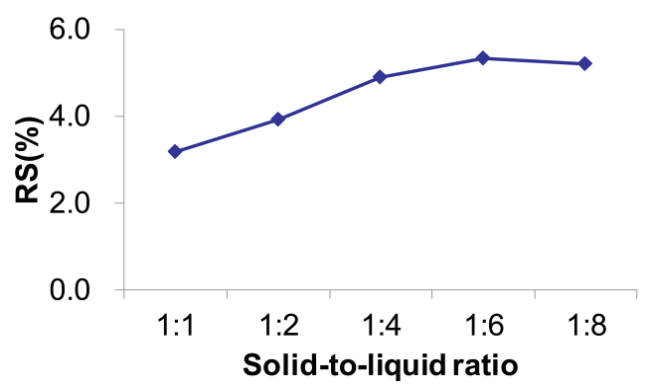

Figure 5: Effects of solid-to-liquid ratio using ultrasonic treatment on buckwheat RS content. 
Citation: Wang L, Bai X (2017) The Producing Technology of Resistant Starch from Buckwheat Using Ultrasonic Treatment. Agrotechnology 6: 161. doi: 10.4172/2168-9881.1000161

Page 3 of 3

\begin{tabular}{|c|c|c|c|c|}
\hline \multirow{2}{*}{ Level } & A & B & C & D \\
\cline { 2 - 5 } & Power (W) & $\begin{array}{c}\text { Ultrasonic } \\
\text { frequency } \\
\text { (KHz) }\end{array}$ & $\begin{array}{c}\text { Solid-liquid } \\
\text { ratio }\end{array}$ & $\begin{array}{c}\text { Treatment time } \\
\text { (min) }\end{array}$ \\
\hline 1 & 200 & 28 & $01: 04$ & 10 \\
\hline 2 & 300 & 40 & $01: 06$ & 20 \\
\hline 3 & 400 & 63 & $01: 08$ & 30 \\
\hline
\end{tabular}

Table 1: Factor level table.

\begin{tabular}{|c|c|c|c|c|c|}
\hline S. No. & $\begin{array}{c}\text { A } \\
\text { Power } \\
\mathbf{( W )}\end{array}$ & $\begin{array}{c}\text { Ultrasonic } \\
\text { frequency (KHz) }\end{array}$ & $\begin{array}{c}\text { Solid-liquid } \\
\text { ratio }\end{array}$ & $\begin{array}{c}\text { Treatment time } \\
\text { (min) }\end{array}$ & (\%) \\
\hline 1 & $1(200)$ & $1(28)$ & $1(1: 4)$ & $1(10)$ & 5.93 \\
\hline 2 & $1(200)$ & $2(40)$ & $2(1: 6)$ & $2(20)$ & 6.95 \\
\hline 3 & $1(200)$ & $3(63)$ & $3(1: 8)$ & $3(30)$ & 6.84 \\
\hline 4 & $2(300)$ & $1(28)$ & $2(1: 6)$ & $3(30)$ & 7.14 \\
\hline 5 & $2(300)$ & $2(40)$ & $3(1: 8)$ & $1(10)$ & 7.07 \\
\hline 6 & $2(300)$ & $3(63)$ & $1(1: 4)$ & $2(20)$ & 7.73 \\
\hline 7 & $3(400)$ & $1(28)$ & $3(1: 8)$ & $2(20)$ & 7.32 \\
\hline 8 & $3(400)$ & $2(40)$ & $1(1: 4)$ & $3(30)$ & 6.89 \\
\hline 9 & $3(400)$ & $3(63)$ & $2(1: 6)$ & $1(10)$ & 6.67 \\
\hline K1 & 19.72 & 20.39 & 20.55 & 19.67 & - \\
\hline K2 & 21.94 & 20.91 & 20.76 & 22 & - \\
\hline K3 & 20.88 & 21.24 & 21.23 & 20.87 & - \\
\hline R & 2.22 & 0.85 & 0.68 & 2.33 & - \\
\hline
\end{tabular}

Table 2: $L_{9}\left(3^{4}\right)$ RS processing orthogonal experiment design and results.

As the results shown in the Table 2, ultrasonic treatment time had the largest effect on RS content. Ultrasonic Power had the second largest effect on RS content. Ultrasonic frequency had the third largest effect on RS content. Solid-liquid ratio had the fourth largest effect on RS content. The optimum parameters for producing technology of resistant starch from buckwheat using ultrasonic treatment are $\mathrm{D} 2 \mathrm{~A} 2 \mathrm{~B} 3 \mathrm{C} 3$, that is ultrasonic treatment time is $20 \mathrm{~min}$, ultrasonic Power is $300 \mathrm{~W}$, ultrasonic frequency is $63 \mathrm{KHz}$, Solid-to-liquid ratio 1:8. The sequence of effects on RS content: $\mathrm{D}>\mathrm{A}>\mathrm{B}>\mathrm{C}$.

\section{Conclusion}

The major factors on RS content using ultrasonic treatment are ultrasonic treatment time, microwave power, ultrasonic frequency, and solid-to-liquid ratio. The optimum parameters for producing technology of resistant starch from buckwheat using ultrasonic treatment are ultrasonic treatment time is $20 \mathrm{~min}$, ultrasonic Power is $300 \mathrm{~W}$, and ultrasonic frequency is $63 \mathrm{KHz}$, Solid-to-liquid ratio 1:8.

\section{Acknowledgement}

This work was supported by the PhD Start-up Fund of Natural Science Foundation under Grant 801100010121.

\section{References}

1. Escarpa A, Gonzalez MC, Morales MD, Saura-Calixto F (1997) An approach to the influence of nutrients and other food constituents on resistant starch formation. Food Chem 60: 527-532.

2. Hasjim J, Lee SO, Hendrich S, Setiawan S, Ai Y, et al. (2010) Characterization of a novel resistant-starch and its effects on postprandial plasma-glucose and insulin responses. Cereal Chem 87: 257-262.

3. Han KH, lijuka M, Shimada KI, Sekikawa M, Kuramochi K, et al. (2005) Adzuki resistant starch lowered serum cholesterol and hepatic 3-hydroxy-3methylglutaryl-CoA mRNA levels and increased hepatic LDL-receptor and cholesterol 7a-hydroxylase mRNA levels in rats fed a cholesterol diet. Brit $J$ Nutr 94: 902-908.
4. Martinez-Puig D, Mourot J, Ferchaud-Roucher V, Anguita M, Garcia F, et al. (2006) Consumption of resistant starch decreases lipogenesis in adipose tissues but not in muscular tissues of growing pigs. Livest Sci 99: 237-247.

5. Higgins JA, Jackman MR, Brown IL, Johnson GC, Steig A, et al. (2011) Resistant starch and exercise independently attenuate weight regain on a high fat diet in a rat model of obesity. Nutr Metab 8: 49.

6. Burn J, Bishop DT, Chapman PD, Elliott F, Bertario L, et al. (2011) A randomized placebo-controlled prevention trial of aspirin and/or resistant starch in young people with familial adenomatous polyposis. Cancer Prev Res 4: 655-665.

7. Birkett AM, Mathers JC, Jones GP, Walker KZ, Roth MJ, et al. (2000) Changes to the quantity and processing of starchy foods in a Western diet can increase polysaccharides escaping digestion and improve in vitro fermentation variables. Br J Nutr 84: 63-72.

8. Lesmes U, Beards EJ, Gibson GR, Tuohy KM, Shimoni E (2008) Effects of resistant starch type III polymorphs on human colon microbiota and short chain fatty acids in human gut models. J Agr Food Chem 56: 5415-5421.

9. Phillips J, Muir JG, Birkett A, Lu ZX, Jones GP, et al. (1995) Effect of resistant starch on fecal bulk and fermentation-dependent events in humans. American J Clin Nutr 62: 121-130.

10. Yonekura L, Suzuki H (2005) Effects of dietary zinc levels, phytic acid and resistant starch on zinc bioavailability in rats. Eur J Nutr 44: 384-391.

11. Robertson MD, Bickerton AS, Dennis AL, Vidal H (2005) Insulin-sensitizing effects of dietary resistant starch and effects on skeletal muscle and adipose tissue metabolism. Am J Clin Nutr 82: 559-567.

12. Zhang ZL, Zhou ML, Tang Y, Li FL, Tang YX, et al. (2012) Bioactive compounds in functional buckwheat food. Food Res Int 49: 389-395.

13. Yadav BS, Sharma A, Yadav RB (2009) Studies on effect of multiple heating/ cooling cycles on the resistant starch formation in cereals, legumes and tubers. Int J Food Sci Nutr 60: 258-272.

14. Leeman AM, Karlsson ME, Eliasson AC, Bjorck IM (2006) Resistant starch formation in temperature treated potato starches varying in amylose/ amylopectin ratio. Carbohyd Polym 65: 306-313.

15. Ring SG, Gee JM, Whittam M, Orford P, Johnson IT (1988) Resistant starch: its chemical form in foodstuffs and effect on digestibility in vitro. Food Chem 28: 97-109.

16. Englyst HN, Veenstra J, Hudson GJ (1996) Measurement of rapidly available glucose (RAG) in plant foods: a potential in vitro predictor of the glycaemic response. Brit J Nutr 75: 327-337.

17. Eerlingen RC, Crombez M, Delcour JA (1993) Enzyme-resistant starch .1. quantitative and qualitative influence of incubation-time and temperature of autoclaved starch on resistant starch formation. Cereal Chem 70: 339-344.

18. Berry CS (1986) Resistant starch-formation and measurement of starch that survives exhaustive digestion with amylolytic enzymes during the determination of dietary fiber. J Cereal Sci 4: 301-314.

19. Mangala SL, Udayasankar K, Tharanathan RN (1999) Resistant starch from processed cereals: the influence of amylopectin and non-carbohydrate constituents in its formation. Food Chem 64: 391-396.

20. Escarpa A, Gonzalez MC (1997) Technology of resistant starch. Food Sci Technol Int 3: 149-161

21. Torre M, Rodriguez AR, Sauracalixto $F$ (1992) Study of the interactions of calcium-ions with lignin, cellulose, and pectin. J Agr Food Chem 40: 1762-1766.

22. Gelencser T, Gal V, Salgo A (2008) Effects of applied process on the in vitro digestibility and resistant starch content of pasta products. Food Bioprocess Tech 3: 491-497.

23. Mulinacci N, leri F, Giaccherini C, Innocenti M, Andrenelli L, et al. (2008) Effect of cooking on the anthocyanins, phenolic acids, glycoalkaloids, and resistant starch content in two pigmented cultivars of Solanum tuberosum L. J Agr Food Chem 56: 11830-11837.

24. McCleary BV, McNally M, Rossiter P, Aman P, Amrein T, et al. (2002) Measurement of resistant starch by enzymatic digestion in starch and selected plant materials: collaborative study. J Aoac Int 85: 1103-1111. 